\title{
De JGZ-professional van de toekomst: van nazorg naar voorzorg
}

\author{
Vasanthi lyer · Ingeborg Tönis · Jolanda Keijsers
}

Published online: 12 September 2018

(C) Bohn Stafleu van Loghum is een imprint van Springer Media B.V., onderdeel van Springer Nature 2018

\begin{abstract}
Samenvatting De zorg moet veranderen, wil ze toekomstbestendig zijn. De zorg is te duur en niet in staat om grote, vaak complexe gezondheidsproblemen het hoofd te bieden. De focus zal meer moeten liggen op preventie, aangeduid met 'van nazorg naar voorzorg'. Dit vraagt van professionals een andere mindset, andere competenties en een andere manier van professionaliseren. Hoe denken de professionals daar zelf over? TNO onderzocht dit in een verkennend onderzoek, toegespitst op het Jeugdgezondheidszorg (JGZ)domein.
\end{abstract}

\section{Beweging van nazorg naar voorzorg}

Professionals in de zorg doen hun werk in een dynamische omgeving. De samenleving verandert, er is een groeiende zorgvraag met complexe problematiek, kennis veroudert snel en technologische veranderingen voltrekken zich in rap tempo. Om de zorg betaalbaar, toegankelijk, dichtbij de patiënt en van hoge kwaliteit te houden, wordt gepleit voor duurzame investeringen in gezondheid en preventie: de beweging van nazorg naar voorzorg [1]. Het belang hiervan wordt breed onderkend. De JGZ-professional wordt opgeleid om een breed arsenaal van medische en niet-medische competenties (bijvoorbeeld op het vlak van samenwerking, communicatie en professionaliteit) te beschikken. Om mee te gaan in de beweging naar gezondheid en preventie is het echter van belang dat JGZ-professionals over aanvullende vaardigheden beschikken. Preventie staat ook centraal in

V. Iyer $(\bowtie) \cdot$ I. Tönis

Jeugd en Gezondheid/Onderwijs, TNO, Leiden, Nederland vasanthi.iyer@tno.nl

Dr. J. Keijsers

TNO, Leiden, Nederland het visiedocument voor de medisch specialist 2025, opgesteld door de Federatie van Medisch Specialisten [2]. Meer investeren in preventie heeft gevolgen voor de rol en competenties van professionals. De NPHF Federatie voor Gezondheid introduceerde in dit kader zes richtinggevende vaardigheidsgebieden (zie tab. 1; [1]).

Op dit moment wordt van alle professionals in de zorg verwacht dat ze voldoen aan een veelheid van professionele eisen. Ze dienen zich te blijven ontwikkelen, ook op de meer op voorzorg gerichte vaardigheidsgebieden [3].

\section{Kaders voor opleiden en professionaliseren}

Hieronder wordt beschreven aan welke competenties artsen, in het bijzonder jeugdartsen, op dit moment moeten voldoen.

In het opleidingenlandschap van de zorg spelen de zogenoemde CanMEDS-competenties (een raamwerk uit Canada) een grote rol [4]. Deze competenties betreffen de eigenschappen waarover een arts moet beschikken om zijn vak goed te kunnen uitoefenen. Er zijn zeven CanMEDS-competentiegebieden: medisch handelen, communicatie, samenwerking, kennis en wetenschap, maatschappelijk handelen, organisatie en professionaliteit. Deze competentiegebieden zijn voor ieder specialisme (dus ook voor jeugdartsen) uitgewerkt in specifieke competenties en spelen een centrale rol in opleidingen, bij- en nascholing en herregistratie. De CanMEDS zijn ook een inspiratiebron voor het opleiden van andere professionals binnen de JGZ, zoals (jeugd)verpleegkundigen.

Van jeugdartsen (net als bij artsen van andere specialismen) wordt verwacht dat zij zich permanent professionaliseren. Het fundament daarvoor wordt gelegd tijdens de twee jaar durende opleiding tot jeugdarts KNMG (als entree-eis geldt een voltooide stu- 
Tabel 1 Zes richtinggevende vaardigheidsgebieden [1]

\begin{tabular}{|l|l|}
\hline $\begin{array}{l}\text { Van } \\
\text { Behandelen van ziekten en bestrij- } \\
\text { den van symptomen }\end{array}$ & $\begin{array}{l}\text { Naar } \\
\text { Duurzaam stimuleren van gezond- } \\
\text { heid en welbevinden }\end{array}$ \\
\hline $\begin{array}{l}\text { Ziekte centraal } \\
\text { Individugericht centraal }\end{array}$ \\
\hline Probleemgericht & $\begin{array}{l}\text { Individu in zijn omgeving en met zijn } \\
\text { systeem }\end{array}$ \\
\hline Solistisch werken & $\begin{array}{l}\text { Benutten van kansen en mogelijkhe- } \\
\text { den }\end{array}$ \\
\hline Analoog werken & Interdisciplinair samenwerken \\
\hline
\end{tabular}

die geneeskunde tot basisarts). Artsen in opleiding (aios) reflecteren tijdens hun opleiding geregeld op hun professionele ontwikkeling met betrekking tot de CanMEDS-competenties. Ook zetten zij jaarlijks een feedbackronde uit onder cliënten, collega's en andere zorgprofessionals met wie zij samenwerken (bijvoorbeeld een jeugdverpleegkundige, een orthopedagoog en zorgcoördinator van een school). Om hun eigen leerproces te sturen houden aios een Persoonlijk Ontwikkel Plan (POP) bij, ook wel Individueel ontwikkelplan (IOP) genoemd.

\section{Herregistratie-eisen}

$\mathrm{Na}$ afronding van de opleiding gaat het leerproces door. In verband met herregistratie-eisen tonen artsen periodiek aan dát ze zich professioneel ontwikkelen en hoe zij dat doen. Vanaf 2020 is naast regelmatige (zelf)evaluatie van het functioneren ook het bijhouden van een POP verplicht [5]. De evaluatieresultaten (bijvoorbeeld uit $360^{\circ}$ feedback) geven input aan het POP, dat als vliegwiel functioneert voor verdere professionele ontwikkeling.

\section{Opleiderscompetenties}

Eisen aan professionalisering gelden ook voor de opleiders. Een opleider begeleidt de aios in de praktijk en vervult daarbij een rolmodelfunctie. Zij leidt jeugdartsen op om samen met andere professionals toekomstbestendige zorg te verlenen. Om dat goed te kunnen doen, is zij op de hoogte van de laatste ontwikkelingen in de zorg en maakt zij een vertaalslag naar de begeleiding van de aios, werkt ze transparant, stelt ze zich toetsbaar op en reflecteert ze op haar eigen functioneren als opleider. Het Landelijk Professionaliseringsplan Praktijkopleiders (LPP) dat per januari 2018 is ingegaan sluit aan bij deze principes. Het bijhouden van een POP gericht op het ontwikkelen van opleiderscompetenties maakt hier deel van uit [6].

Zoals het voorbeeld in het kader laat zien spelen opleiders een belangrijke rol: als begeleider, coach én rolmodel.

\section{Leven lang leren}

Zowel bij aios, artsen als praktijkopleiders wordt door middel van periodieke evaluatie van het functioneren vormgegeven aan een 'leven lang leren'. Toegespitst op de JGZ-professional verloopt dit proces volgens de volgende principes:

- rekening houden met ontwikkelingen in de context van de JGZ;

- in een cyclisch proces reflecteren op de eigen professionele ontwikkeling;

- conclusies trekken voor professionaliseringsactiviteiten;

- deze activiteiten uitvoeren en daar weer op reflecteren.

Dit cyclische proces staat steeds in het teken van het uiteindelijke doel van het werk van de professional: dié kwaliteit bieden die nodig is om optimaal bij te dragen aan een gezonde en veilige opgroeisituatie van jeugdigen, als individu en als groep [7].

\section{Verkennend onderzoek Leven Lang Leren}

Het POP vormt een hulpmiddel bij het leven lang leren. Maar een POP is niet meer dan een lege huls, totdat het door de professional wordt gevuld. Dán krijgt het betekenis. Maar waar moet een leven lang leren dan over gaan? En welke tools zijn daarbij behulpzaam?

TNO ging hierover in gesprek met JGZ-professionals. De centrale vraag was: hoe kan een leven lang leren worden ingericht om toekomstbestendige zorg te realiseren en te behouden?

In eerste instantie zijn negen individuele interviews gehouden, waarbij de volgende functies vertegenwoordigd waren: jeugdarts in opleiding, jeugdarts KNMG, arts maatschappij \& gezondheid, stafarts, praktijkopleider van jeugdartsen in opleiding, instituutsopleider, opleidingscoördinator van een GGD en JGZ-beleidsadviseur. Bij sommige geïnterviewden was sprake van gecombineerde functies. De uitkomsten van de interviews zijn in een bredere groep stakeholders uit de JGZ besproken, waaraan een deel van de geïnterviewden én nieuwe stakeholders deelnamen.

\section{Resultaten}

Hieronder worden de uitkomsten en discussiepunten van de interviews en stakeholdersbijeenkomsten samengevat.

\section{Eigen regie op nummer 1}

Professionals hechten veel waarde aan de eigen regie op een leven lang leren. Niet alleen professionaliseren omdat dit nodig is voor registratiepunten, maar nadrukkelijk ook om zich op basis van reflectie op het eigen handelen verder professioneel te ontwikkelen. 


\section{Praktijkvoorbeeld van een opleidingssituatie}

Luuk volgt de opleiding tot jeugdarts KNMG. Het praktijkdeel van deze opleiding doet hij in een JGZorganisatie waarbij hij wordt begeleid door een praktijkopleider.

Het valt de praktijkopleider op dat Luuk een voorkeur heeft voor de spreekkamer. Bij opdrachten op het terrein van medisch handelen doet hij meer dan gevraagd wordt. Taken waarbij hij moet samenwerken met andere professionals (bijvoorbeeld in een interdisciplinair samenwerkingsverband) schuift hij voor zich uit. In een gesprek confronteert de praktijkopleider Luuk met dit gedrag en vraagt ze door om hem aan te zetten tot reflectie. Luuk beaamt dat zijn interesse vooral uitgaat naar medisch handelen. Samenwerken vindt hij lastig en dat geldt vooral voor interdisciplinair samenwerken. De praktijkopleider benadrukt het belang van samenwerken om kwalitatief goede zorg te kunnen bieden, nu en in de toekomst. Ze bespreken de mogelijkheden om zijn competenties op het terrein van samenwerken verder te ontwikkelen. Het gesprek sluit af met de afspraak dat Luuk binnen twee weken een verslag van het gesprek met concrete acties en een planning mailt.

\section{Competenties en zes richtinggevende vaardigheidsgebieden}

In de gesprekken kwam naar voren dat reflectie en professionaliseringsactiviteiten betrekking moeten hebben op de CanMEDS-competenties én de zes door de NPHF benoemde richtinggevende vaardigheidsgebieden. Hoewel jeugdartsen al meer aan de preventiekant werken, zijn de individuele verschillen soms groot. Digitaal werken en interdisciplinaire samenwerking verdienen meer aandacht. De zes vaardigheidsgebieden zouden ook onderwerp van gesprek moeten zijn in (interdisciplinair) samenwerkende teams.

\section{Leren tijdens en van het werk, óók samen met anderen}

In het algemeen leren professionals het meest van het samen in de praktijk met elkaar doen, geïntegreerd in het werk. Voorbeelden die genoemd zijn: een workshop geven, een collega coachen, meewerken aan de ontwikkeling van een richtlijn, participeren in een interdisciplinair netwerk en dat nabespreken met een collega. 'Een congres of bijeenkomst bijwonen kan zeker nuttig zijn voor het op de hoogte raken van nieuwe ontwikkelingen, nieuwe werkwijzen en dergelijke. Omgaan hiermee leer ik door ermee aan de slag te gaan op mijn werk en daarop te reflecteren.'
Praktijkvoorbeeld van een opleidingssituatie (vervolg)

Luuk richt zich het liefst op 'medisch handelen'. De spreekkamer is zijn comfortzone. Om toekomstbestendige zorg te kunnen verlenen is het ook belangrijk dat hij samenwerkt met professionals binnen en buiten de GGD, een actieve rol vervult in een interdisciplinair samenwerkingsverband, 'de wijk' in gaat en medisch leiderschap toont. Als eerste stap moet hij zich bewust worden van het belang van dit alles. Zijn praktijkopleider helpt hem hierbij door passende vragen te stellen, feedback te geven en hem te stimuleren tot reflectie, die hij vervolgens kan gebruiken om zijn POP aan te passen. Daar leert Luuk van, het helpt hem een goede arts te worden, een professional die de toekomst aan kan.

De praktijkopleider benut dit proces ook voor haar eigen professionalisering. Ze reflecteert op haar competenties en coachende vaardigheden en hoe zij deze kan verbeteren, vervolgens past ze haar POP aan. Over twee weken is het volgende voortgangsgesprek met Luuk. Verkregen inzichten zal zij dan benutten, en later ook in de coaching van andere aios.

\section{Anticiperen op ontwikkelingen}

Een leven lang leren mag zich niet beperken tot kennis en vaardigheden met betrekking tot vraagstukken en ontwikkelingen in de zorg die op dat moment spelen. Juist het signaleren van nieuwe ontwikkelingen, daarmee omgaan én daarop anticiperen door passende professionaliseringsactiviteiten te kiezen, zijn vaardigheden die passen bij de professional van de toekomst.

\section{Digitaal portfolio als tool}

Veel aios werken hier al mee; voor specialisten en opleiders van artsen is dit instrument in opmars. De bij het onderzoek betrokken professionals zien een digitaal portfolio als een goed hulpmiddel bij de vormgeving van een leven lang leren. Met behulp van het digitaal portfolio werkt de arts of opleider aan zijn POP. Onmisbare elementen van het digitaal portfolio als input voor het POP zijn: $360^{\circ}$ feedback en een competentiespinnenweb (of staafdiagrammen), waarmee de professional zijn ontwikkeling met betrekking tot de competenties zichtbaar maakt. Via een afgeschermd deel moet een deel van de informatie voor herregistratiedoeleinden kunnen worden gebruikt.

\section{Veiligheid}

De deelnemers aan het onderzoek wijzen op voorwaarden verbonden aan het gebruik van een digitaal portfolio. 'Voor mijn professionele ontwikkeling is het 
van belang dat ik me kwetsbaar kan opstellen. Dat anderen zomaar zonder toestemming daarin kunnen meekijken, vind ik niet acceptabel.'

Tegelijkertijd zien professionals het voordeel van het organisatiebreed invoeren van dit instrument. De organisatie beschikt op die manier over managementrelevante informatie en kan daar het opleidingsbeleid op afstemmen. Hierbij geldt als voorwaarde dat de toepassing veilig en anoniem is.

\section{Toekomstmuziek}

Velen willen nog een stap verder gaan dan de inzet van een digitaal portfolio. Men is gecharmeerd van een breder opgezet digitaal platform. Op zo'n platform kunnen de ontwikkeling van competenties, reflectie, feedback, intercollegiale toetsing en coaching een plek krijgen. Professionals (al dan niet van verschillende disciplines) kunnen op het platform met elkaar kennis delen en zelfs in interactie met elkaar nieuwe kennis ontwikkelen.

\section{Beschouwing}

In de JGZ werken jeugdartsen, jeugdverpleegkundigen, verpleegkundig specialisten en (dokters)assistenten. De jeugdarts onder hen beschikt over een brede sociaal-geneeskundige kennis en vaardigheden op het gebied van het opgroeiende kind. Als aangewezen specialist ondersteunt de jeugdarts kinderen, jongeren en hun ouders bij gezond opgroeien, gezondheidsbedreigingen, ziekte en ontwikkelingsproblematiek. Met preventie, (vroeg)signalering, begeleiding, behandeling en gerichte verwijzing is de jeugdarts verantwoordelijk voor tijdige en adequate toegang tot en gebruik van de zorg- en hulpverlening [8]. De huidige jeugdarts staat midden in het gemeentelijk speelveld en onderhoudt een dynamische relatie met jeugdteams. Samenwerken met ketenpartners is hierbij onontbeerlijk. Minder snel medicaliseren van problemen, een effectieve aanpak van schoolverzuim op scholen en het realiseren van zorg op maat dichtbij de leefomgeving vragen bovendien om een intensievere samenwerking met netwerkpartners.

Bij het toekomstbestendig maken en houden van de zorg spelen preventie en professionalisering een grote rol. Tijdens het opleiden van aios en opleiders wordt hier dan ook meer en meer aandacht aan besteed. Artsen blijven zich na hun registratie als specialist of profielarts voortdurend ontwikkelen in de CanMEDScompetenties $\mathrm{Zij}$ bekwamen zich niet alleen op het gebied van medisch handelen, maar ook in de zogenoemde non-technical skills. Kennis verwerven, kennis overdragen, vaardigheden trainen, werken aan een professionele houding en vakinhoudelijke ontwikkeling zijn daarbij belangrijke aspecten.

De professional van de toekomst ontwikkelt zich, afgezien van de CANMeds, ook op de zes vaardig- heidsgebieden zoals die zijn geformuleerd door de NPHF. De uitgangssituatie op deze vaardigheidsgebieden en de mate waarin deze vaardigheden van belang zijn, zal per specialisme en ook daarbinnen variëren. Zo werken jeugdartsen per definitie al meer aan de preventiekant dan bijvoorbeeld een neuroloog. En de ene jeugdarts is de andere niet. In alle gevallen is reflectie op de vaardigheidsgebieden (waar bevind ik me nu, waar wil/kan ik heen en hoe) een inspiratiebron voor verdere professionalisering. Dat geldt niet alleen voor individuele professionals, maar ook voor (interdisciplinair) samenwerkende teams.

De resultaten van het verkennend onderzoek geven aan hoe de respondenten onder de JGZ-professionals in de publieke gezondheidszorg aankijken tegen de invulling hiervan. Een digitaal portfolio kan een handig en nuttig instrument zijn voor jeugdartsen en opleiders om vorm te geven aan het POP. Dit zal dan een op leren gericht instrument moeten zijn, waarbij er voldoende ruimte is voor 'eigen regie'. Het is interessant om na te gaan in hoeverre de opvattingen, zoals weergegeven in de resultaten, worden gedeeld door andere beroepsgroepen en specialismen binnen de JGZ, bijvoorbeeld jeugdverpleegkundigen en hun opleiders. Zowel ontwikkelaars als toekomstige gebruikers van digitale portfolio's zijn immers gebaat bij een goede aansluiting van dit instrument bij wensen en verwachtingen.

\section{Literatuur}

1. Plochg T, Keijsers J, Wigersma L. Toekomstbestendige zorg: van visie naar actie! Tijdschr Gezondheidswet. 2017;95:63-6.

2. Federatie medisch specialisten. Visiedocument medisch specialist 2015. 2015. https://www.demedischspecialist. $\mathrm{nl} /$ sites/default/files/Visiedocument\%20Medisch\% 20Specialist\%202025-DEF.pdf. Geraadpleegd op: 4 jun 2018.

3. Vliet Kvan, Grotendorst A, Roodbol P. Anders kijken, anders leren, anders doen. Grensoverschrijdend leren en opleiden in zorg en welzijn in het digitale tijdperk. Commissie InnovatieZorgberoepen en Opleidingen. Diemen: Zorginstituut Nederland; 2016.

4. KNMG. Algemene competenties van de medisch specialist, CanMEDS. 2018. http://www.van-osch.com/ knmgcanmeds.htm. Geraadpleegd op: 4 jun 2018.

5. College Geneeskundige Specialismen (CGS). Besluit herregistratie specialisten. 2015. https://www.knmg.nl/web/ file. Geraadpleegd op: 4 jun 2018.

6. Landelijk Professionaliseringsplan Praktijkopleiders, bestuurlijk vastgesteld door de KAMG, NVVG/GAV, NVAB: 23 oktober 2017. https://www.nvvg.nl/files/120/20171031 \%20LPP.pdf. Geraadpleegd op 4 juni 2018.

7. Beschrijving doel en organisatie van de Jeugdgezondheidszorg. https://www.ncj.nl/over-ncj/organisatie/ jeugdgezondheidszorg/. Geraadpleegd op 4 juni 2018.

8. Beroepsvereniging AJN Jeugdartsen Nederland. Wat doet de jeugdarts. 2018. http://ajnjeugdartsen.nl/dejeugdarts/wat-doet-de-jeugdarts/2018. Geraadpleegd op: 4 jun 2018. 